\title{
Future orientation and fertility: cross-national evidence using Google search
}

\author{
Nicolò Cavalli ${ }^{1,2, *}$
}

\begin{abstract}
Using digital traces to investigate demographic behaviours, I leverage in this paper aggregated web search data to develop a Future Orientation Index for 200 countries and territories across the world. This index is expressed as the ratio of Google search volumes for 'next year' (e.g., 2021) to search volumes for 'current year' (e.g., 2020), adjusted for country-level internet penetration rates. I show that countries with lower levels of future orientation also have higher levels of fertility. Fertility rates decrease quickly as future orientation levels increase; but at the highest levels of future orientation, this correlation flattens out. Theoretically, I reconstruct the role that varying degrees of future orientation might play in fertility decisions by incorporating advances in behavioural economics into a traditional quantity-quality framework à la Becker.
\end{abstract}

Keywords: future orientation; total fertility rate; hyperbolic discounting; quantityquality trade-off; digital trace data; Google trends; digital demography

\section{Introduction}

"Demographic behaviour has a future orientation. People marry, cohabit, have children, divorce or migrate primarily because they have expectations or hopes about how the particular demographic change will affect their lives" (McDonald 1996, 385). While the idea that fertility choices involve an orientation towards the future is rarely disputed, it is seldom incorporated into models of childbearing decisions. Research on fertility as a future-oriented behaviour has typically focused on intentions in terms of ideals regarding optimal family size and the timing of

\footnotetext{
${ }^{1}$ Nuffield College, University of Oxford, UK

${ }^{2}$ Carlo F. Dondena Centre for Research on Social Dynamics and Public Policy, Università Commerciale Luigi Bocconi, Milano, Italy

*Correspondence to: Nicolò Cavalli, nicolo.cavalli@nuffield.ox.ac.uk
} 
childbearing (Bongaarts 1990). These intentions have been shown to correlate to the number of children at the individual level (Westoff et al. 1957; Schoen et al. 1999; see Morgan 2001 for a review), as well as to fertility rates at the broader society level (Goldstein et al. 2003; Hagewen and Morgan 2005). The literature has generally seen intentions as rooted in a variety of micro- and macro-level factors (Balbo et al. 2013), such as the prevailing gender equity level (Mills et al. 2008), socio-economic characteristics (Régnier-Loilier et al. 2011) and the contextual life course events of parents (Liefbroer 2009).

Emphasising instead the role that subjective factors may play, some studies have drawn on social psychology, and particularly on Ajzen's (1991) theory of planned behaviours, to argue that life course transitions can be better understood if greater reflexivity is assumed at the level of the decision-maker (Billari et al. 2009; Ajzen and Klobas 2013; Mencarini et al. 2015; see Philipov 2011 for a discussion). Drawing on these intuitions, I investigate in this paper the role that future orientation plays in fertility. Relying on advances in the field of behavioural economics, I conceptualise future orientation as a form of discounting. In particular, I discuss how varying degrees of intensity in the preference for rewards that happen sooner rather than later can affect childbearing in the heuristic context of a traditional quantity-quality framework à la Becker.

Analytically, I follow Billari's (2015) two-stage approach to explaining demographic change, which requires linking the production of evidence at the population level to micro-funded theories of individual behaviour. Indeed, according to Goldthorpe (2016), social research should seek to make population regularities both 'visible', i.e., by uncovering macro-level patterns that would be apparent in a general form to any equipped observer; and 'transparent', i.e., by determining the process by which those regularities that are established at the aggregate level are rooted in the actions and interactions of individual agents. Thus, after discussing why different degrees of preference for the present relative to the future may affect fertility from a theoretical, micro-level standpoint, I investigate the empirical relationship between a measure of future orientation and fertility rates at the population level.

Drawing from Preis et al. (2012), I leverage Google Trends volumes, and construct a Future Orientation Index as the ratio of the volume of Google searches for the 'next year' (a number) to the volume of Google searches for the 'current year' (also a number) for 200 countries and territories across the world in the reference years 2010 to 2016. I estimate that the digital trace data I employ to build this index capture the aggregate online search behaviour of about 2.3 billion individuals, or $31 \%$ of the world's population. However, because internet access is very unequal across the globe, I build on methods developed by Zagheni and Weber $(2012,2015)$ to correct this index in order to better account for biases in the generation of Google data. Based on this corrected measure, I document that countries that display lower levels of future orientation have higher levels of fertility. Fertility rates decline quickly as future orientation levels increase, but at higher levels of future orientation, this negative correlation flattens out. I conclude by reviewing the limitations of using Google Trends data for fertility research, and by proposing that further research 
grounded at the micro level should be carried out in order reconstruct the role of future orientation in shaping demographic behaviour.

\section{Theoretical background}

\subsection{Fertility as a future-oriented behaviour}

The intuition that fertility intentions and behaviours entail an element of orientation towards the future can be traced back to seminal discussions of declining birth rates during the period when Europe and North America were undergoing the demographic transition. Frank Notestein famously stated that "the reduction of fertility requires a shift in social goals", brought about "in response to drastic changes in the social and economic setting" (Notestein 1945, 40). As Kirk (1996, 364) noted, Notestein drew from Carr-Saunders (1922), who focused on the role of customs and codes of conduct in regulating fertility in pre-transition societies in his book The Population Problem. By contrast, Caldwell $(1976,325)$ criticised this "Malthusian" emphasis on "attitudes, beliefs, traditions and irrationality", and instead stressed the role of rational choice in fertility behaviours. Building on Simon (1974), who argued that "fertility is everywhere subject to much rational control", Caldwell $(1976,355)$ observed that "fertility is high or low as a result of economic benefit to individuals, couples, or families in it being so".

According to Caldwell, fertility intentions primarily depend on the benefits of childbearing, which are, in turn, determined by the direction and the magnitude of intergenerational wealth flows, and their net balance, "from parents to children and from children to parents - over the period from when people become parents until they die" (Caldwell 1976, 344). Economic formulations of Caldwell's intuition model fertility as stemming from the maximisation of a dynastic utility function, based on the consumption of agents at one point in time, and on the consumption of the agents' descendants from that point in time into the future (Becker and Barro 1986). In such a framework, the decision of a couple to start having children is determined by the employment prospects of children, the monetary and psychological costs of avoiding childbearing (Becker 1960), and the interaction between the quantity and the quality of children (Becker and Lewis 1973). It follows that fertility declines if the relative price of having children increases, if income falls, or if there is a change in the shape of the couple's utility function for children versus for other goods (McDonald 2001).

Most recently, the evidence that that a number of countries are moving towards having low and lowest-low fertility levels has renewed the debate over whether economic rationality represents a satisfying explanatory principle when seeking to account for these developments (Caldwell and Schindlmayr 2003; Billari et al. 2004; Caldwell and Schindlmayr 2004; Caldwell 2004). Lutz et al. (2006) outlined a sociological driver of change by proposing that the formation of family size 
ideals is supported through socialisation, and is passed on from one cohort to another. The role played by normative pressures has been also integrated into social psychological models, with extensive references to Ajzen's (1991) theory of planned behaviour. This theory posits that social norms interact with the economic benefits of childbearing perceived by prospective parents, and with the control that they believe they have over their desired behaviours (see, e.g., Philipov et al. 2006; Billari et al. 2009). Sobotka $(2009,390)$ has suggested that when faced with eroding social norms against childlessness and having only one child, young adults may "reduce their fertility intentions by becoming more realistic when assessing their fertility goals, taking into account competing lifestyle alternatives and their growing awareness of different obstacles that may unfold later in life".

A connected but relatively unexplored dimension of fertility intentions is how actual behavioural control might moderate the impact of intentions on behaviours. Actual behavioural control refers to the ability to perform a desired action, and, in the case of childbearing, has been variously defined as determined by internal and external constraints, such as wealth, income, employment, education, housing and health status (Billari et al. 2009, 447; see also Schoen et al. 1999, 791). According to Ajzen (2011), a further moderating factor in the intention-behaviour nexus is the ability of individuals to self-regulate. Departing from McEachan et al. (2011), who reviewed empirical evidence indicating that the association between intentions and behaviours weakens with the temporal distance between the measurement of an intention and the observation of a behaviour, Ajzen $(2011,1115)$ pointed out that "as time passes, an increasing number of intervening events can change people's behavioural, normative or control beliefs, modify attitudes, subjective norms or perceptions of control, thus generating revised intentions".

In this paper, I draw from advances in the field of behavioural economics to offer a simple analytical operationalisation of behavioural control. In particular, I focus on the role played by time discounting, or the preference for gratification sooner rather than later (Hariri et al. 2006). Ubiquitous in human decision-making, discounting may lead individuals to opt for rewards that happen sooner but are smaller, rather than for rewards that are larger but delayed. For example, a person might favour a $\$ 100$ reward today over a $\$ 110$ reward tomorrow. ${ }^{1}$ Empirically, rates of discounting are found to decline over time. Following on the previous example, individuals might indeed prefer getting $\$ 100$ today to receiving $\$ 110$ tomorrow, but may be willing to wait 31 days to get $\$ 110$ if the alternative is getting $\$ 10030$ days from now. In other words, willingness to wait increases as a function of the expected delay in getting the reward (Loewenstein and Thaler 1989).

Crucially, this discount structure, which is also called 'hyperbolic discounting', creates "a conflict between today's preferences, and the preferences that will be held in the future" (Laibson 1997, 445). According to Loewenstein and Thaler (1989,

\footnotetext{
Experimental studies have found that discounting decreases with the size of the reward; i.e., the larger the reward is, the more willing individuals are to wait (Ainslie 1975).
} 
186), "if the discount rate declines over time, people will always consume more in the present than called for by their previous plans". ${ }^{2}$ Thus, time discounting can be seen as a realistic integration of the classical assumption of rationality of economic agents, or as way of incorporating the role of 'impatience' into analyses of human decision-making (Thaler 1981; 2018). While discounting has been investigated in a wide variety of settings, from saving to health behaviours (Strotz 1955; Laibson 1997; Barro 1999; Harris and Laibson 2001; Gruber and Kôszegi 2002; Diamond and Kôszegi 2003; Barlow et al. 2016), and particularly with regard to the implications for households in developing economies (Banerjee and Mullainathan 2010), little attention has been paid to the role discounting might play in childbearing decisions.

\subsection{Hyperbolic discounting and the quantity-quality trade-off}

To the best of my knowledge, only three previous studies have investigated the childbearing implications of discounting (Wrede 2011; Wigniolle 2013; Robson and Szentes 2014). Among these studies, Wrede (2011) and Wigniolle (2013) derived analytical solutions from a standard quantity-quality trade-off à la Becker, augmented by adding (quasi-)hyperbolic discounting to the utility function of a unitary household. Quasi-hyperbolic discounting penalises future rewards by a coefficient $\beta k^{t}$, composed by a constant factor, $\beta<1$, which captures the presence of a negative preference for delays; and by an exponential factor, $k^{t}$, for any $t>0$, which grows at a constant rate as the time from the reward increases. By setting $\beta k=1$, this utility formulation is equivalent to that of a rational agent, while a fully hyperbolic formulation of the discount factor, such as $\left(\frac{1}{1+k t}\right)^{\beta / \alpha}$, with $\beta$ and $\alpha$ greater than zero, can also be used to capture decreasing rates of discounting.

To analyse the childbearing implications of discounting, I build on Wigniolle $(2013,72)$, and depart from a unitary household model with three periods. The number of children (quantity) is set in the first period, while the quality is set in the second period. Because parents may be assumed to want children, each child enters positively the utility of the household in period 1, but at an opportunity cost in terms of consumption due to the resources devoted to childrearing. In the second period, the household selects the level of 'quality', which also entails a consumption tradeoff because investing in children is costly. In the third and final period, the quantity and the quality jointly enter the household's utility. This may reflect the altruism of parents who value both the number and the quality of their children, or the fact

\footnotetext{
2 Referring to the choice between $\$ 110$ in 31 days and $\$ 100$ in 30 days, it has been pointed out that while hyperbolic discounters might choose to wait 31 days to get $\$ 110$, as the $30^{\text {th }}$ day approaches, impatience sometimes kicks in, leading them to take the smaller $\$ 100$ reward.
} 
that children may represent an investment good, as they can provide support to their ageing parents (Wrede 2011, 1056-1057). ${ }^{3}$

In this toy model, the representative household chooses the optimal number of children by maximising the instantaneous utility obtained across all three periods. In this simple set-up, quasi-hyperbolic discounting has straightforward implications: by penalising rewards that come later rather than sooner, it implies that the benefits of quantity, which enter utility in period 1, bear more weight in the household's maximisation problem than the benefits of quality, which enter utility in period 2 . Thus, ceteris paribus, a 'hyperbolic discounter' household will invest relatively more in quantity than in quality. The main hypothesis is as follows: countries characterised by a greater bias towards the present (less future-oriented) will also have higher total fertility rates (TFR) than countries that are less present-biased (more future-oriented) (Hypothesis 1).

Given that in Becker's framework, quantity and quality are connected through the intertemporal budget constraint, setting a higher number of children in period 1 may lead the household to resort to a dynamic inconsistent solution in terms of quality - i.e., a lower-than-desired investment - in period 2, which is a feature of hyperbolic discounting. At the same time, because hyperbolic discounting implies that time preferences decrease over time, a higher level of future orientation - i.e., a greater willingness to wait - may lead the household to appreciate the prospect of receiving more benefits at a later point in time. This can be thought of as a shift in the relative weight of period 3. Thus, as the bias towards the present decreases (future orientation increases), the relative weight of future periods for the household's utility also increases, leading households to appreciate the benefits of old-age support (or of altruism) more. Because in this model the benefits of oldage support (altruism) are determined by both quality and quantity, a highly futureoriented household might have more children than a moderately future-oriented household. I therefore expect that at high levels of future orientation, the negative relationship between future orientation and fertility reverses (Hypothesis 1a).

\section{Data and methods}

\subsection{The Future Orientation Index}

Through their digital behaviour, internet users leave traces that can be leveraged to measure their relative interest in the present, the past or the future. Preis et al. (2012) argued that the levels of relative interest in the future or in the past can be

\footnotetext{
3 In period 3, the observation that both quantity and quality enter a household's utility function may be interpreted as indicating that a positive rate of investment in quality influences children's survival probability, their human capital, their future income, and other factors that are relevant for subsequent intergenerational transfers.
} 
Figure 1:

Evolution of Google queries for a given 'number-year', 2012-2017, worldwide

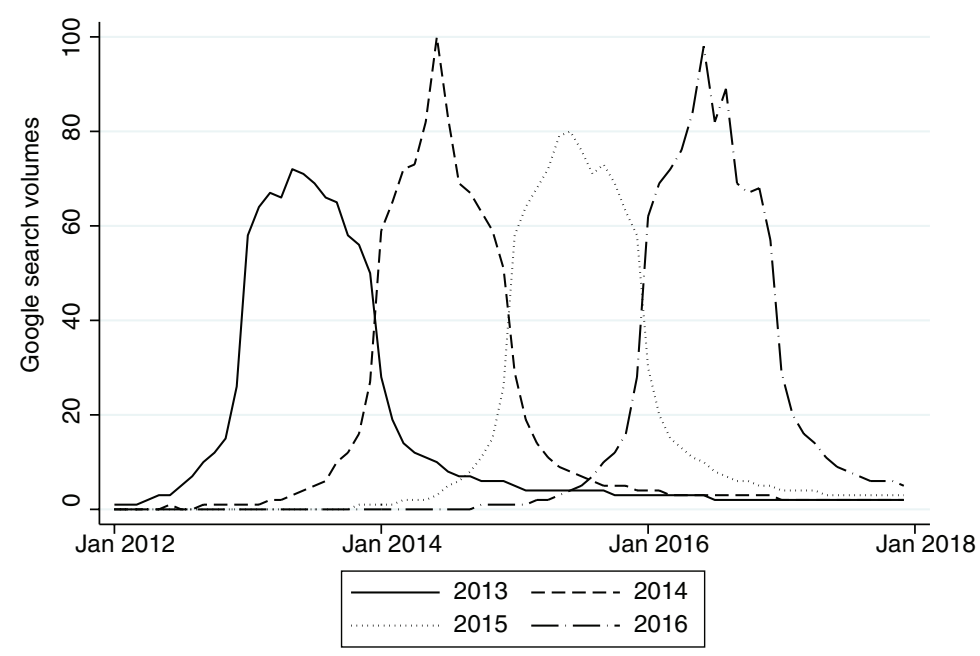

measured by comparing the volume of searches for specific 'years'. Exploiting the fact that Arabic numerals are widely used across the world, they built a 'future orientation index' as the ratio of Google search volumes for future $(t+1)$ and past $(t-1)$ 'number-years' (e.g., interest in 2021 compared to interest in 2019, with reference $t=2020$ ). In Figure 1, I show how interest in different 'number-years' varies across time by plotting monthly worldwide search volumes for the numbers '2013', '2014, '2015' and '2016', from 1 January 2012 to 31 December 2017. ${ }^{4}$ I obtained these volumes through Google Trends, which draws from a subsample of all the queries submitted to Google.com. Search volumes are divided by the total number of searches, and then rescaled from zero to 100; thus, they represent a measure of the relative interest in specific keywords in a specific time period and geography.

Looking at Figure 1, it is possible to observe that queries for the 'number' capturing a given year start rising during the immediately preceding months, with a peak corresponding to December of the previous year. The relative interest in a given 'number-year' remains relatively stable throughout the following months, with peaks related to specific events. In 2014, for example, the male 2014 FIFA World Cup caused a surge in searches for '2014' during the summer months of that same year. However, as a new year approaches, searches for the current 'numberyear' start declining quickly, while searches for the next 'number-year' rise. After

4 Google Trends, Google Inc. Retrieved on 14 May 2019. Available at: https://trends.google.com/ 
each year has passed, the respective 'number-year' searches stabilise at low levels with long right tails, which indicates continuous interest in past events. This pattern is quite regular across the six years of data plotted in Figure 1. Throughout the same period, it can also be observed that searches for the present (current 'number-year') systematically outnumber searches for both the past and the future.

In this paper, I leverage cross-country variations in relative interest in the future rather than in the present, and use it as a proxy of future orientation. In particular, I propose a country-year measure of future orientation leveraging Google search data from 2010 to $2016 .{ }^{5}$ This Future Orientation Index is computed as the ratio of the aggregated yearly volume of Google search queries for the 'next year' to Google search queries for the 'current year', corrected for differentials in internet adoption rates across countries. Formally, this can be written as:

$$
\begin{aligned}
F_{j t}= & \frac{\text { Google Search for } t+1_{j t}}{\text { Google Search for } t_{j t}} \\
& \times \frac{\% \text { InternetUsers } j t-\min (\% \text { InternetUsers })}{\max (\% \text { Internet } U \text { sers })-\min (\% \text { InternetUsers })}
\end{aligned}
$$

where $F O I_{j t}$ is the Future Orientation Index for a given year $(t)$ and country $(j)$. Equation (1) is composed of two terms. The first term captures the relative interest in the immediate 'future' compared to in the 'present'. In 2016, for example, future orientation is captured as the ratio of the aggregated country-level volume of searches for the keyword '2017' to the aggregated country-level volume of searches for the keyword '2016'. Relative to the measure devised by Preis et al. (2012), comparing searches for the present $(t)$ and the future $(t+1)$, as proposed in Equation (1), has the advantage of yielding a measure that is directly interpretable in terms of a more theoretically relevant 'bias towards the future'.

\subsection{Correcting for internet penetration}

In Equation (1), the second term corrects raw 'future orientation' for cross-country differentials in internet penetration, as these differences might introduce biases into the representativeness of the data. The share of the population with internet access varies considerably across counties: in 2016, this figure ranged from $1.17 \%$ for Eritrea to $98.24 \%$ in Iceland. Wide differentials in internet access raise two issues: a) an instability bias, as short-run variations in internet access might make within-country year-to-year comparisons less meaningful; and b) a selective adopter bias, as internet usage and access are not orthogonal to individual-level characteristics that are likely to be correlated with future orientation, such as income and education. Therefore, especially in countries with low internet penetration,

5 Google Trends, Google Inc. Retrieved from: https://trends.google.com/ between February 2016 and April 2019. 
the observed volumes might be skewed towards specific demographics, such as towards individuals who are younger, more educated and more urban, and who might therefore display higher levels of future orientation compared to the baseline for the country.

Several methods have been proposed to address bias in non-representative internet samples (see Zagheni and Weber 2015 for a discussion). The correction proposed in Equation (1) equals one in the country-year with the highest proportion of internet users, and moves towards zero as the percentage of internet users declines. Therefore, the magnitude of the change in the raw future orientation measure for each country is inversely proportional to the rate of internet adoption: for high values of adoption, $F O I_{j t}$ will not differ substantially from the raw future orientation measure. This follows from the assumption that the representativeness of the data increases as the internet adoption rate rises. Reflecting the further assumption of a negative monotonic relationship between individual-level future orientation and the likelihood of having internet access, the raw future orientation measure is reduced proportionately as the percentage of internet users declines. I repeat the procedure set out in Equation (1) for 200 countries and territories across the world in any given year from 2010 and 2016, and report summary statistics of this FOI in Table 2.

Because my weighting approach always returns low FOI values for those countries with low internet penetration rates, social and economic development factors that are related to modernisation, and are thus associated with both fertility and internet penetration rates, might lead to omitted variable bias when testing for the correlation between the future orientation measure and fertility at the country level. To test the robustness of my findings, I employ in this paper two sets of alternative future orientation measures. The first is the uncorrected FOI based on raw Google Search volumes. The second set of measures is obtained by multiplying my raw FOI by the correction factor proposed by Zagheni and Weber (2012). This correction factor $(\mathrm{CF})$ can be written as:

$$
C F=\frac{p_{j}\left(e^{-k}-1\right)}{\left(e^{-k p_{j}}-1\right)}
$$

where $p_{j}$ is the internet penetration rate by country $(j)$ and $k$ is a parameter that captures the intensity of the selective adopter bias. ${ }^{6}$ According to Zagheni and Weber $(2012,351)$, "the parameter $k$ determines how fast the selection bias increases with a decrease in Internet penetration rates. Low values of $k$ imply that the selection bias is small, even at very low Internet penetration rates. Conversely, high values of $k$ mean that the selection bias increases substantially when Internet penetration rates become lower". Thus, varying the value of $k$ allows me to account for varying

\footnotetext{
6 Zagheni and Weber (2012) additionally correct for the internet penetration by age and gender, thus using the formula $C F=\frac{p_{g a j}\left(e^{-k}-1\right)}{\left(e^{-k p_{g a j}}-1\right)}$, where $g$ represents the gender-specific internet penetration rate and $a$ represents the age-specific internet penetration rate.
} 
Table 1:

Correlations by weighting procedure

\begin{tabular}{lc}
\hline & Raw future orientation \\
\hline Preis et al. (2012) & 1.000 \\
CF, $k=0.005$ & 0.972 \\
CF, $k=0.05$ & 0.476 \\
CF, $k=0.5$ & 0.290 \\
CF, $k=5$ & 0.282 \\
CF, $k=50$ & 0.282 \\
FOI & 0.279 \\
\hline
\end{tabular}

degrees of (unobserved) self-selection in the sample. Following Zagheni and Weber (2012), I experiment with several values of the $k$ parameter $(k=0.005 ; k=0.05 ; k=$ $0.5 ; k=5 ; k=50) .^{7}$ Finally, I also use the naïve procedure proposed by Preis et al. (2012), who excluded countries with less than five million internet users from their sample. The correlation coefficients between these corrected FOI and the raw measure given by $F O I_{j t}=\frac{\text { Google Search for } t+1_{j t}}{\text { Google Search for } t_{j t}}$ are reported in Table 1 .

\subsection{Validation of the Future Orientation Index}

To further stress the appropriateness of my measure for capturing future orientation, I validate my index of country-level FOI against 'ground truth' data. In Figure 2, I plot the country-year FOI thus obtained with the Long-Term Orientation Index proposed by Hofstede (1991), and measured by Galor and Özak (2016) based on Wave 1 to 5 (1981-2009) of the World Value Survey (WVS), for 87 countries across the world. ${ }^{8}$ This Long-Term Orientation Index (LTO) was constructed based on the following WVS item: "Here is a list of qualities that children can be encouraged to learn at home. Which, if any, do you consider to be especially important?" As explained in Galor and Özak (2016, S93), "An individual is considered to have LongTerm Orientation if she answered 'Thrift, saving money and things' as an especially important quality children should learn at home". The country-level LTO also spans from zero to 100 , and has been shown to correlate with national saving rates and other theoretically relevant macro-level outcomes (Hofstede et al. 2010, 38). The Pearson's coefficient for the correlation between FOI and LTO is 0.43 .

\footnotetext{
7 Notice that Zagheni and Weber $(2015,315)$ constrain the $k$ parameter between the values 0.5 and 100.

8 Galor and Özak (2016), Additional Materials - Dataset. Retrieved on 23 April 2019. Available at: https://www.aeaweb.org/articles?id=10.1257/aer.20150020.
} 
Figure 2:

External validation of the Future Orientation Index

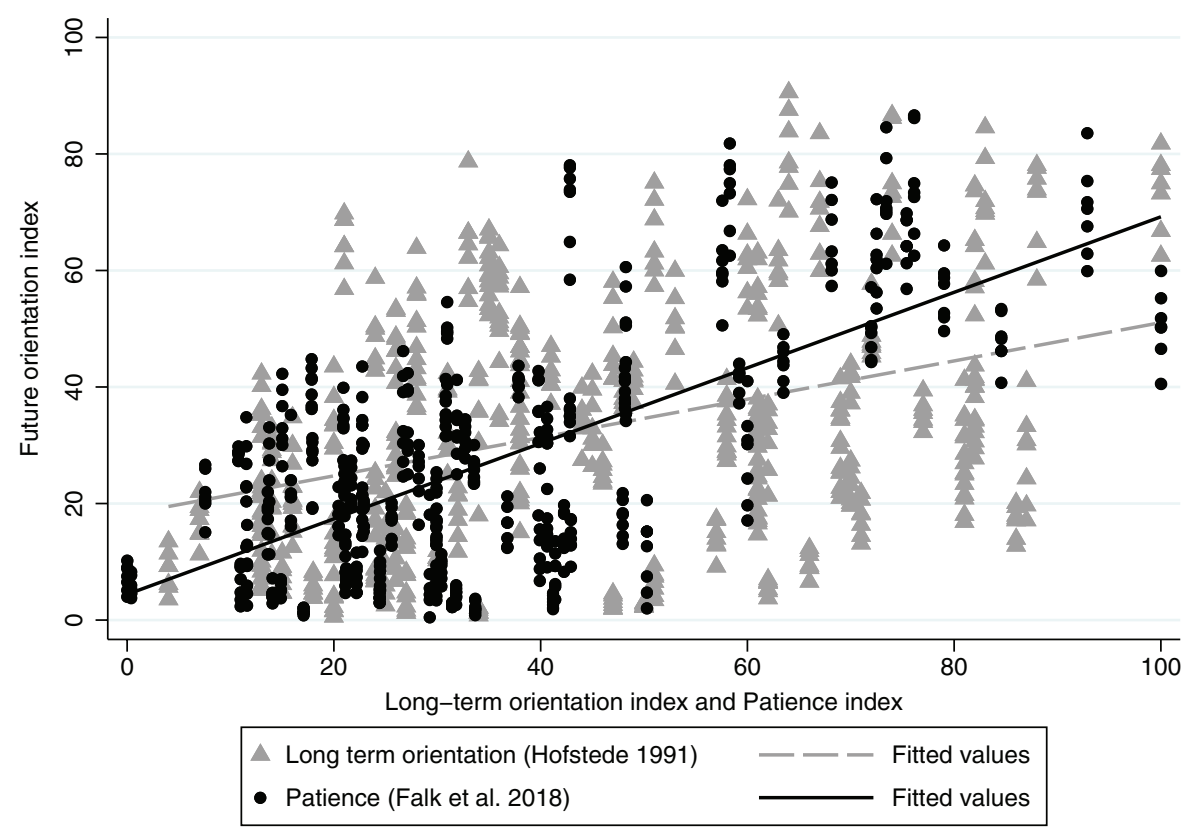

As can be seen from Figure 2, I also validate my FOI against a measure of time preference obtained from the Global Preference Survey (GPS), a large international survey covering 80,000 respondents in 76 countries that represent approximately $90 \%$ of the world's population (Falk et al. 2016, 2018). ${ }^{9}$ In the GPS, the measure of time preference, or 'patience', is derived from the combination of responses to a quantitative and a qualitative survey: in the quantitative survey, respondents were confronted with a series of five interdependent binary choice tasks in which they had to decide between receiving a payment today or larger payments in 12 months. In the qualitative survey, respondents were asked to self-assess their 'willingness to wait' on an 11-point Likert scale, based on the following question: "How willing are you to give up something that is beneficial for you today in order to benefit more from that in the future?" The two sets of responses were then combined with a 71\% weight assigned to the quantitative survey (Falk et al. 2018, 1653-1654). I find that the FOI, based on volume data from Google Search and corrected for internet adoption rates, correlates positively and strongly with the GPS's measure of patience (with a 0.70 Pearson correlation coefficient).

9 Global Preference Survey (GPS). Retrieved on 23 April 2019. Available at: https://www.briqinstitute.org 


\subsection{Identification strategy}

In the next section, I test for the correlation between future orientation and fertility by fitting a standard OLS model with country and year fixed effects, where countryyear TFR ${ }^{10}$ is regressed on the FOI obtained from Equation (1). To account for confounders, I include in the model a range of country-level covariates: i.e., with the aim of controlling for a country's population structure, I include population size $^{11}$ and the age-dependency ratio. ${ }^{12}$ I also control for a country's level of socioeconomic development by adding a measure of gross domestic product (GDP), ${ }^{13}$ expressed in constant 2010 United States dollars, as well as the widely used Human Development Index (HDI). ${ }^{14}$ The HDI has been employed in demographic research to describe the transition from high to low fertility (Bongaarts and Watkins 1996), as well as to outline a recent reversal and the non-linearity of the HDI-fertility relationship (Myrskylä et al. 2009). Consistent with this literature, I allow for a nonlinear effect of the HDI on fertility through the inclusion of a squared HDI variable. Furthermore, the inclusion of country-level fixed effects allows me to control for geographic characteristics that are stable across time, while the inclusion of year fixed effects allows me to account for the existence of idiosyncratic time factors that are related to events that shift interest globally.

Despite using information on internet adoption to correct the raw FOI obtained from the Google Trends tool, I also include the levels of internet adoption in the country as an additional explanatory variable for fertility (Billari et al. 2019). Unfortunately, not all of these data are available for all of the countries for which the FOI can be computed. In the next section, I present results using all data for all countries in the sample, including for those countries for which some values are missing across the set of controls. Thus, in order to retain the highest statistical power available, the models are tested on marginally varying samples. However, the results are robust when listwise deletion is employed, and the models are estimated only on the subset of countries for which data for all controls and all years are available (not shown). Table 2 presents summary statistics for the variables employed in the following analysis. All analyses are run in STATA v.16/SE.

10 World Bank - Fertility rate, total (births per woman). Retrieved on 8 February 2016. Series updated 19 April 2019. Available at: https://data.worldbank.org/indicator/SP.DYN.TFRT.IN

11 World Bank - World development indicators; Population, total. Retrieved on 21 April, 2019. Available at: https://data.worldbank.org/indicator/SP.POP.TOTL

12 World Bank - World development indicators; Age dependency ratio (\% of working-age population). Retrieved on 23 April 2019. Available at: https://data.worldbank.org/indicator/sp.pop.dpnd

13 World Bank - World development indicators; GDP (constant 2010 US\$). Retrieved on 11 February 2016. Series updated 12 April 2019. Available at: https://data.worldbank.org/indicator/NY.GDP.MKTP. $\mathrm{KD}$

14 United Nations Development Programme - Human Development Reports; Human Development Index. Retrieved on 9 February 2016. Series updated 22 April 2019. Available at: http://hdr.undp.org/ en/data 
Table 2:

Summary statistics

\begin{tabular}{lccccc}
\hline & Mean & Sd & Min & Max & $N$ \\
\hline $\begin{array}{l}\text { Outcome variables } \\
\quad \text { Total fertility rate (TFR) }\end{array}$ & 2.84 & 1.43 & 1.06 & 7.48 & 1328 \\
$\begin{array}{l}\text { Explanatory variable } \\
\quad \text { Future Orientation Index (FOI) }\end{array}$ & 24.92 & 20.90 & 0 & 100 & 1362 \\
$\begin{array}{l}\text { Controls } \\
\quad \text { Internet penetration }\end{array}$ & 42.36 & 29.08 & 0.25 & 98.32 & 1368 \\
$\quad$ Age-dependency ratio & 59.41 & 18.55 & 16.45 & 111.77 & 1290 \\
$\quad$ Population (M) & 35.72 & 136.18 & 0.01 & 1378.66 & 1395 \\
$\quad$ Gross domestic product (GDP \$M) & 369343 & 1413891 & 1.69 & 1853.31 & 1344 \\
$\quad$ Human Development Index (HDI) & 0.69 & 0.15 & 0.31 & 0.95 & 1309 \\
\hline
\end{tabular}

\section{Results}

\subsection{Empirical evidence on cross-country future orientation}

I re-express the FOI obtained from Equation (1) on a zero (maximum present bias) to 100 (maximum future orientation) scale, and plot on a world map the country averages for the period 2010-2016. Overall, the mean FOI value is 24.92 . Even though in all years the searches for the current 'number-year' exceed the searches for the future 'number-year' by 9.49 times on average, the variation in the FOI is fairly large, with a standard deviation of 20.90. The country scoring the highest on the future orientation measure is Lichtenstein (85.79), while the country scoring the lowest is Somalia (0.79). Just as countries vary greatly in their overall economic development and in their stage in the demographic transition, they differ in their future orientation levels as well. The average FOI value for countries classified as 'high-income' by the World Bank is 48.97, whereas the average FOI for 'low-income' countries is only 4.54. Looking at Figure 3, it is also possible to qualitatively observe that the countries with the highest levels of future orientation (Germany, Japan, South Korea) are also characterised by lowest-low fertility, while the countries with high TFRs, such as Sub-Saharan African countries, also tend to have lower levels of future orientation.

In Figure 4, I present some descriptive evidence on the association between the TFR and the FOI from 2010 to 2016 for 200 countries and territories across the world (black circles). The evidence indicates that the TFR quickly declines as the FOI increases. However, this correlation becomes flat when moving towards higher levels of future orientation (lower levels of present bias). In Figure 4, I also separately plot the two elements that constitute the FOI; i.e., the raw search ratio and 


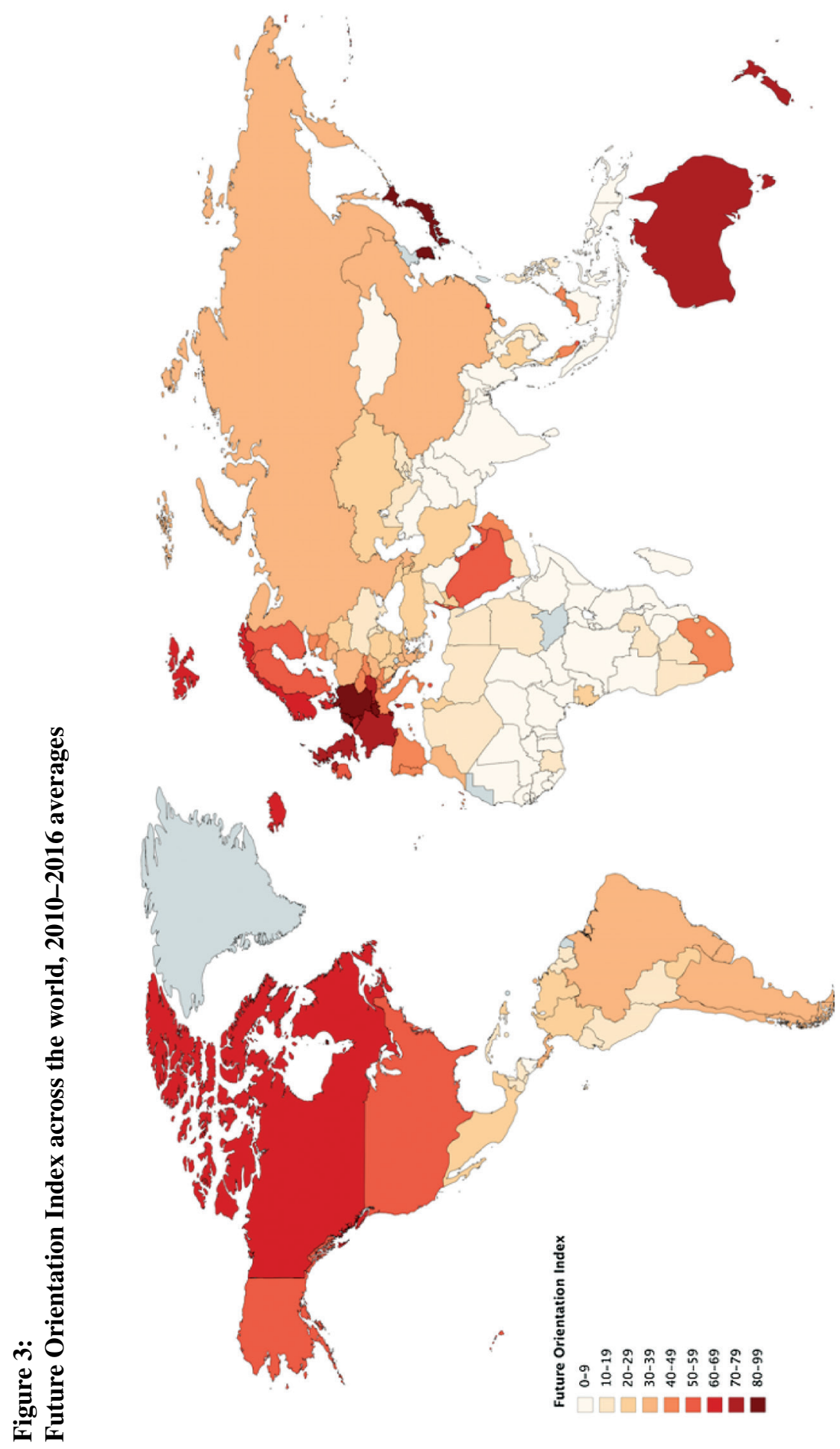


Figure 4:

Future orientation and total fertility rate

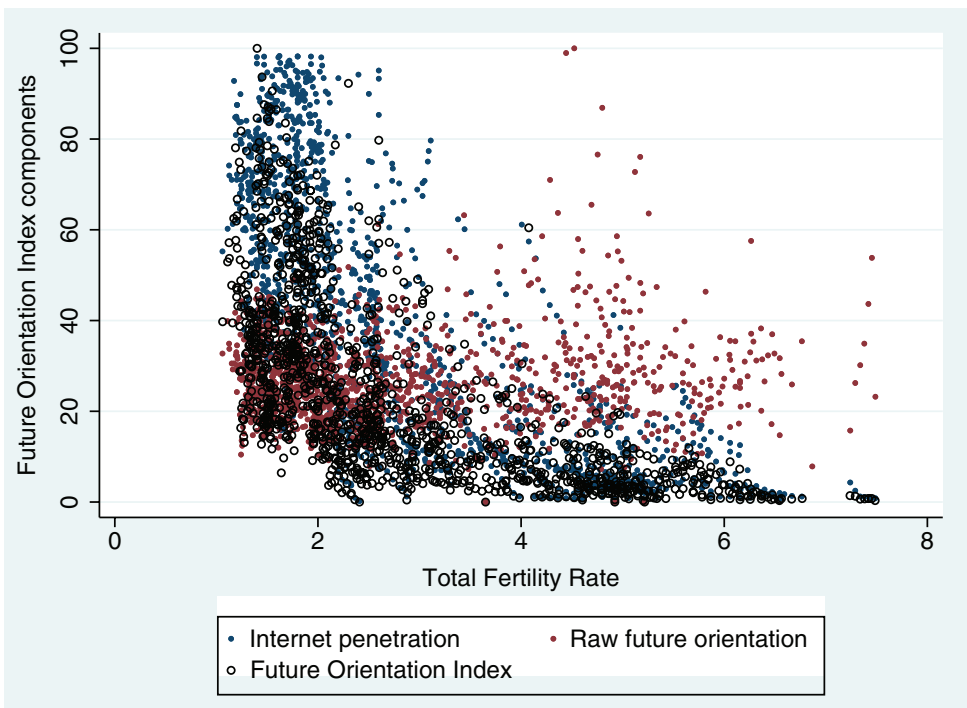

the standardised levels of internet penetration. When looking at these two factors separately, it appears that the shape of the association between the FOI and the TFR is imposed by the distribution of internet penetration levels, while the raw search ratio shows no clear association with the TFR.

In order to verify whether the association between the FOI and the TFR is an artefact created by the way in which the FOI is computed, I plot in Figure 5 the raw search ratio $\left(\frac{\text { Google Search for } t+1_{j t}}{\text { Google Search for } t_{j t}}\right)$ against the TFRs for each country and year by levels of internet penetration $(\leq 20 \%,>20-\leq 40 \%,>60-\leq 70 \%$, and $>80-100 \%$ ). As was discussed in Section 3.2, my correction approach assumes that the representativeness of the data increases with the level of internet adoption. Indeed, at low levels of internet penetration (Internet $<20 \%$ ) the raw Future Orientation Index has a higher degree of variability $(\min =0 ; \max =0.41 ; \mathrm{sd}=$ 0.54), and the association between this search measure and the TFR has a positive slope. ${ }^{15}$ However, at the highest level of internet penetration, a significant negative association seems to appear $(r=-0.2048, p=0.0069)$. In the regression analysis, I experiment with different correction approaches to relax the assumptions driving the correction of Equation (1).

15 I thank an anonymous reviewer and the editors for this part of the analysis. 
Figure 5:

Correlation between TFR and raw search ratio, by levels of internet penetration

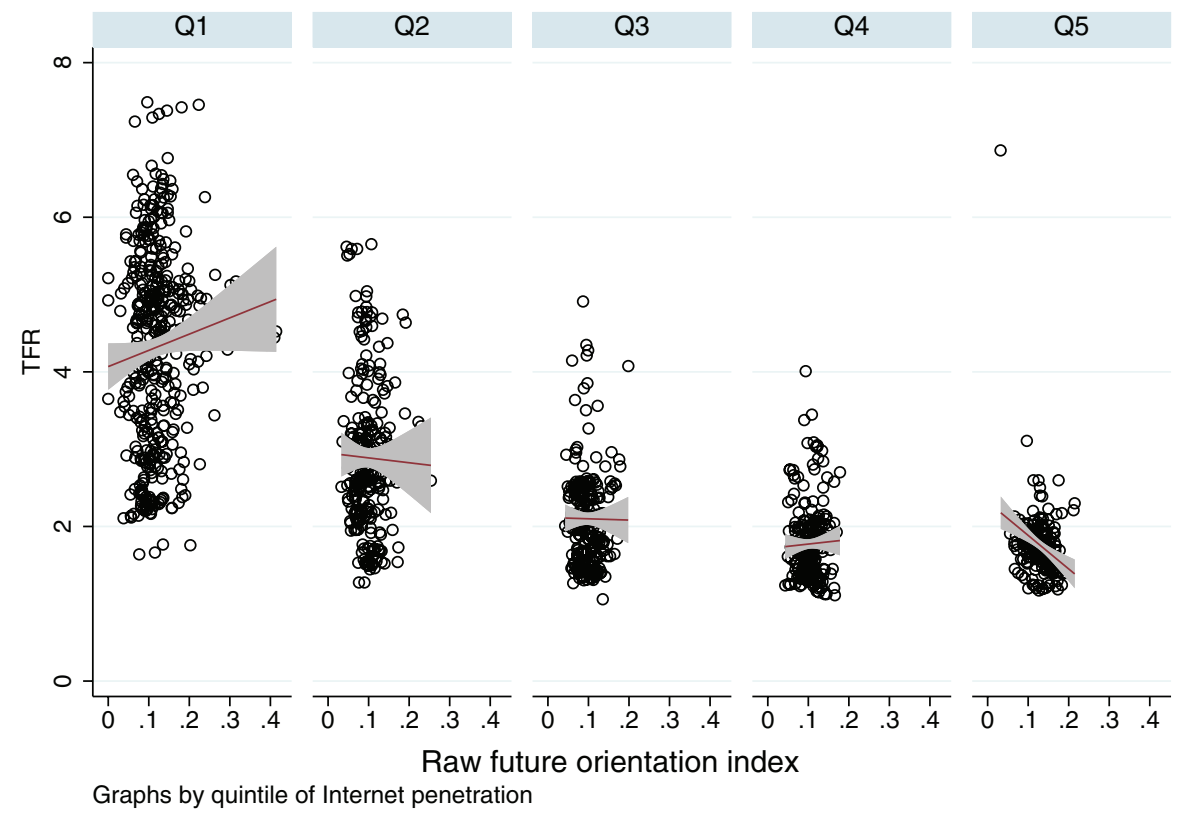

\subsection{Regression analysis}

In Table 3, I show results for the effects of future orientation on total fertility rates. Column (1) regresses the TFR on the FOI only: in line with Hypothesis 1, the coefficient of this relationship is found to be negative and significant at the 0.001 level. The size of the coefficient implies that a one-unit increase in the FOI leads to a 0.04 decrease in the TFR at the country-year level - or that a standard deviation increase in the FOI causes the TFR to decline by 0.8 points on average, ceteris paribus. This result is robust to the inclusion of year- and country-fixed effects. However, the inclusion of these controls shrinks the size of the coefficient, which becomes only marginally significant (Table 3 Column 3 ). The introduction of country-year levels of internet penetration $\left(\beta_{\text {internet }}=0.00, p=9.65\right)$ in the regression equation (Table 3 Column 4 ) decreases the size of the beta coefficient, which also becomes better defined in statistical terms (statistical significance at the 0.001 level).

This result implies that failing to include internet penetration repressed the effect of future orientation on fertility, as the level of internet penetration appears to be negatively correlated with the FOI (implicitly confirming the selectivity of internet users at low levels of internet penetration) and positively correlated with 
Table 3:

Regression analysis: TFR and FOI; world 2010-2016

\begin{tabular}{|c|c|c|c|c|c|c|c|}
\hline & \multicolumn{7}{|c|}{ Total fertility rate } \\
\hline & (1) & (2) & (3) & (4) & (5) & (6) & (7) \\
\hline & \multicolumn{7}{|c|}{ Pane a. Linear model } \\
\hline \multirow[t]{3}{*}{ FOI } & $-0.044^{* * *}$ & $-0.044^{* * *}$ & $-0.001^{* * *}$ & $-0.003^{* * *}$ & $-0.002^{* * *}$ & $-0.002^{* * *}$ & $-0.002^{* * *}$ \\
\hline & $(-30.40)$ & $(-30.61)$ & $(-7.35)$ & $(-5.58)$ & $(-4.93)$ & $(-5.25)$ & $(-4.06)$ \\
\hline & \multicolumn{7}{|c|}{ Pane b. Non-linear model } \\
\hline FOI & $-0.127^{* * *}$ & $-0.127^{* * *}$ & $-0.003^{* *}$ & $-0.009^{* * *}$ & $-0.002^{6 *}$ & $-0.006^{* * *}$ & $-0.004^{* * *}$ \\
\hline & $(-32.61)$ & $(-32.76)$ & $(-2.88)$ & $(-7.02)$ & $(-6.54)$ & $(-6.26)$ & $(-4.04)$ \\
\hline $\mathrm{FOI}^{2}$ & $0.001^{* * *}$ & $0.001^{* * *}$ & $0.000^{* * *}$ & $0.000^{* * *}$ & $0.000^{* * *}$ & $0.000^{* * *}$ & $0.000^{*}$ \\
\hline & $(22.36)$ & $(22.40)$ & $(2.33)$ & $(4.78)$ & $(4.62)$ & $(4.07)$ & $(2.24)$ \\
\hline Dependency & NO & NO & NO & NO & YES & YES & YES \\
\hline Population & NO & NO & NO & NO & YES & YES & YES \\
\hline GDP & NO & NO & NO & NO & NO & YES & YES \\
\hline HDI & NO & $\mathrm{NO}$ & NO & NO & NO & YES & YES \\
\hline $\mathrm{HDI}^{2}$ & NO & $\mathrm{NO}$ & NO & NO & NO & NO & YES \\
\hline Internet & NO & NO & NO & YES & YES & YES & YES \\
\hline Year F.E. & NO & YES & YES & YES & YES & YES & YES \\
\hline Country F.E. & NO & NO & YES & YES & YES & YES & YES \\
\hline$N$ & 1313 & 1313 & 1313 & 1313 & 1285 & 1250 & 1250 \\
\hline
\end{tabular}

Note: $t$ statistics in parentheses; ${ }^{* * *} p<0.001,{ }^{* *} p<0.01,{ }^{*} p<0.05,{ }^{+} p<0.10$.

the TFR. In Table 3 Column 5, I control for the population structure by introducing both the population size and the age-dependency ratio. The inclusion of these additional variables $\left(\beta_{\text {population }}=-0.00, p=-1.06 ; \beta_{\text {dependency }}=0.02, p=18.81\right)$ does not alter the significance of the correlation between the FOI and the TFR, while marginally shrinking the size of the correlation coefficient. In Column 6, I control for socio-economic development by introducing variables capturing the GDP $\left(\beta_{\mathrm{GDP}}=0.00, p=2.11\right)$ and the HDI $\left(\beta_{\mathrm{HDI}}=-9.54, p=-10.68\right)$; while in Column 7, I allow for a non-linear relationship between the TFR and the HDI $\left(\beta_{\text {HDIsq }}=7.23, p=10.70\right)$. The correlation between the FOI and the TFR is robust to the inclusion of these controls. Based on the model of Column 6, I conclude that a one-standard-deviation increase in the FOI decreases the TFR by 0.04 points on average.

I also run a set of regressions fitting a non-linear model of future orientation by allowing a FOI squared $\left(\mathrm{FOI}^{2}\right)$ independent variable to enter the TFR regression (Table 3 Pane b). Even in these models, the FOI is negatively correlated with the TFR. However, the size of the estimated coefficient is noticeably larger across all regressions. Additionally, and consistent with the descriptive evidence presented in Figure 4, I find that at higher levels of future orientation, the correlation with the 
Table 4:

Alternative correction approaches

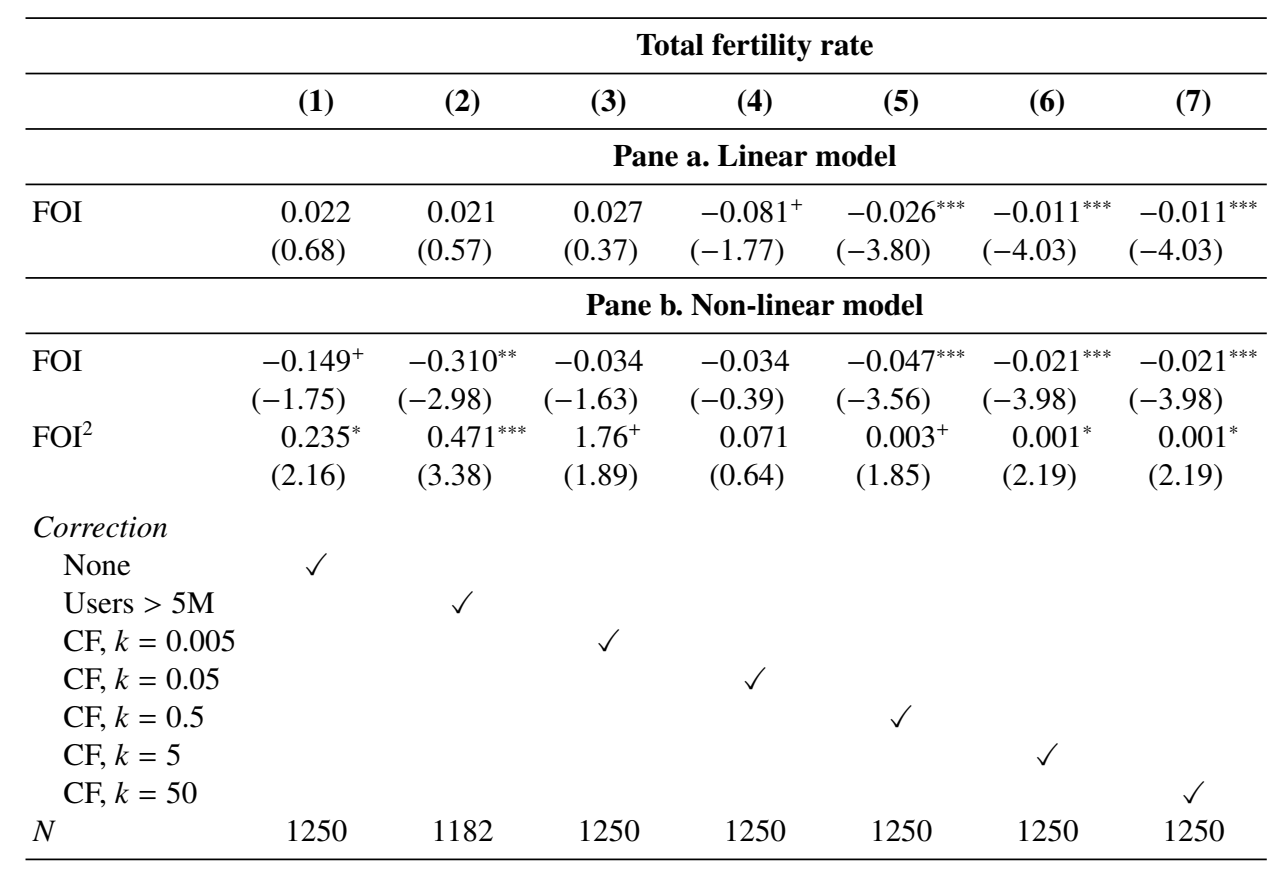

Note: $t$ statistics in parentheses; ${ }^{* * *} p<0.001,{ }^{* *} p<0.01,{ }^{*} p<0.05,{ }^{+} p<0.10$. All models include all controls.

TFR becomes positive. This result is consistent and significant across all models, even when allowing for non-linear effects of socio-economic development through the inclusion in the model of the HDI and the squared HDI, as is done in Column 7 (significant at the 0.05 level). These results are robust to the inclusion of the FOI with a one-year lag as an explanatory variable (not shown). Overall, these results appear to confirm that future orientation is negatively associated with total fertility, but that this relationship ceases to be negative at high FOI levels.

In Table 4, I replicate the model of Equation (1) using alternative future orientation measures. I first experiment using the raw Google Search ratio of 'next year' to 'current year' volumes. In the linear model, the correlation between the raw Google search ratio and the TFT is not significant (Column 1 pane a). However, when allowing for non-linear effects in the relationship between the TFR and future orientation, I observe a negative coefficient significant at the 0.10 level for the FOI, and a positive coefficient significant at the 0.05 level for the $\mathrm{FOI}^{2}$ (Column 1 pane $\mathrm{b}$ ). These results do not change when the sample is restricted to those country-years with internet user numbers above five million, as proposed by Preis et al. (2012). On the other hand, the results from four out of the five correction factors proposed by Zagheni and Weber (2012) confirm that there is a significant and negative correlation 
between the FOI and the TFR in the linear model (Columns 4 to 7). Moreover, the sign and the significance of the coefficients are robust in the non-linear model as well - with the exception of $k=0.05$.

\section{Discussion and Conclusions}

In this paper, I have investigated the relationship between a measure of 'future orientation' and total fertility rates using Google Trends web search data. Before discussing my findings, it should be noted that the study has a number of limitations stemming from the use of online search data. A first general limitation is that the Google Trends volumes, which were used as an explanatory variable, were retrieved on multiple occasions at different points in time from April 2016 to 2019 (see footnote 6 above). This introduces a degree of sampling noise in the datagenerating process. In fact, Google Trends employs a rolling sampling procedure that returns the same result within each day, but slightly different results on different days. Carrière-Swallow and Labbé $(2013,291)$ found that the distribution of measurements has a standard deviation of $5.8 \%$ and a kurtosis above 10 . The estimates presented in this paper are based on the assumption that this measurement variation is random, and is, therefore, captured in the error term of my regression models.

An additional limitation stemming from my use of Google Trends volumes as a predictor is that internet penetration levels vary significantly across countries and time. Throughout the paper, I have repeatedly noted that differences in levels of internet penetration may affect the reliability of my future orientation estimates. I have also proposed a simple method for correcting for cross-country internet penetration, and used this corrected Future Orientation Index in my regression models. However, my correction approach relies on two assumptions: first, that the representativeness of digital data increases with the level of internet adoption; and, second, that there is a negative monotonic relationship between individuallevel future orientation and the likelihood of having internet access. To relax these assumptions, I ran a set of robustness checks that employ alternative correction methods, based on Zagheni and Weber (2012) and Preis et al. (2012). I also used a raw, uncorrected measure of future orientation as the main explanatory variable. The results of these models generally confirmed the robustness of my main findings.

Finally, it should be noted that even within countries with high levels of internet penetration, there are often large divides in digital access across different social groups (see, e.g., Garcia et al. 2018; Fatehkia et al. 2018 for overviews of gender inequalities); and that even in those countries where the population's level of access to the internet is relatively equal, people with different socio-economic characteristics tend to use Google with different intensities, and thus bear different weights in the data-generating process (Ragnedda and Muschert 2013). To address this issue, Zagheni and Weber (2015) proposed further correcting raw digital trace estimates by accounting for differential levels of internet access by gender and age 
within each country. Because of a lack of appropriate data, the internet penetration corrections that I employed in this paper did not account for these additional sources of bias.

Despite these significant limitations, I found that my digital trace-based estimates of future orientation are consistent with Hofstede's (1991) Long-Term Orientation Index and with evidence from Falk et al.'s (2018) Global Preference Survey, which includes high-quality experimental and self-reported measures of time preferences. However, while these latter measures are high-cost, low-frequency indicators because they are based on the availability and the deployment of large-scale social surveys across countries, the Future Orientation Index that I presented is a lowcost, high-frequency measure that allows for replicability and broader worldwide coverage. Estimates from the United Nations' International Telecommunication Union $^{16}$ indicate that around $42 \%$ of the world's population had internet access throughout this time period. With the exception of China, Google is the preferred search engine in every country, with a $90.9 \%$ share of the global online search engine market. ${ }^{17}$ Based on this figure, it can be estimated that the Google Trends data employed in my paper capture the online search behaviour of about 2.3 billion individuals in 200 countries and territories, or $31 \%$ of the world's population (see Bail et al. (2019) for analogous estimates and a discussion).

Using this cross-national longitudinal dataset, I found evidence of a negative correlation between future orientation and total fertility rates at the country level. In a linear regression model, this relationship is robust to country and year fixed effects, and to the inclusion of several country-level controls. Based on the full model, I estimated that on average, a one-standard-deviation increase in the FOI is associated with a 0.04 -point decrease in the TFR. I also tentatively documented a non-linearity in this relationship: at high levels of future orientation, the correlation between the FOI and the TFR flattens out.

In the literature, several other studies have found a similar J-shaped relationship between the TFR and variously conceived measures of development. Myrskylä et al. (2009) found that while increases in development (HDI) generally reduce fertility, at high levels of development, further increases in the HDI reverse the decline. By contrast, Luci-Greulich and Thévenon (2014) as well as Esping-Andersen and Billari (2015) pointed to the role of gender equality, arguing that after a certain level of development, the ongoing female revolution reverses fertility decline. Finally, Aassve et al. (2016) rationalised such trends by referring to generalised social trust, and its role in moderating the fertility implications of women's educational expansion. Rather than arguing that future orientation represents an alternative

16 World Bank data based on the International Telecommunication Union, World Telecommunication/ICT Development Report and database. Internet users are defined as individuals who have used the internet in the last three months from any device, including a computer, a mobile phone, a personal digital assistant, a gaming machine, or a digital TV. Retrieved on 22 April 2019. Available at: https://datacatalog.worldbank.org/internet-users-100-people-2

17 Retrieved from Statcounter.com on 27 April 2020. 
theoretical paradigm, I propose that considering the role played by time preferences can add another theoretical micro-foundation to the mechanisms that link individual fertility decisions to institutional factors that operate at the macro level.

For example, at the macro level, an initial implication of the quantity-quality tradeoff with hyperbolic discounting is that for any level of present bias, a unit increase in the cost of investing in quality leads to lower desired fertility. Thus, education represents a commitment technology; i.e., a device that exogenously constrains the future decisions of households by introducing a lower bound to the resources devoted to investing in quality. This implies that households that have the same level of present bias, but that are subject to different levels of required investments in human capital, generally as a function of the degree of development in a country or of specific institutional settings, will have very different fertility outcomes. A second implication concerns the role that economic institutions, such as capital markets, might play in altering the time horizon of prospective parents. By shifting the costs of childrearing to the future, a fully functioning capital market allows households to increase both quality and quantity - the only two factors that jointly enter the household's utility at the third and final period - at an intertemporal rate of substitution equal to the interest rate.

At the micro level, high rates of discounting have also been linked to several suboptimal behaviours, such as under-saving (Strotz 1955; Laibson 1997), smoking (Gruber and Kőszegi 2002), and having an unhealthy diet (Barlow et al. 2016), with particularly adverse implications for poor households in developing countries (Banerjee and Mullainathan 2010). As I discussed above, if households cannot anticipate future alterations in preferences, those engaged in hyperbolic discounting might have a higher-than-optimal number of children, which would result in a lower-than-optimal level of quality. Thus, examining the role present bias plays in fertility decisions might shed some light on the mechanisms that underlie the observed empirical correlation between household size and poverty (Lanjouw and Ravallion 1995). According to Haushofer and Fehr $(2014,866)$, poverty has distinct neurological effects, including a higher aversion to risk and a stronger preference for short-term rewards.

This paper represents only a tentative first step towards the development of a research programme that incorporates the role that future orientation plays in childbearing decisions. Furthermore, limitations in the currently available methods for extracting comparably meaningful signals across regions with different levels of internet penetration, and the nature of this paper's empirical approach, do not allow me to make any causal claims regarding the relationship between the TFR and the FOI. However, while research on fertility has had the advantage of relying on data that are available across countries and time, including objective macro- and microlevel determinants, measures of more subjective factors, such as those related to future orientation, have so far been elusive, especially across time and space. With this paper I have argued that digital trace data could prove helpful in this research domain. However, the use of digital traces in demographic and fertility research 
presents a number of challenges, some of which I discussed in this paper, that should be carefully and openly debated.

\section{Acknowledgments}

I wish to thank Francesco C. Billari for his early suggestions on the development of the paper; the organisers, Emilio Zagheni and Bogdan State; and the participants of the Workshop on Social Media and Demographic Research, held in Cologne on 17 May 2016, where seminal ideas for this paper were presented and discussed for the first time. I also wish to thank the anonymous reviewers and the editors of the Vienna Yearbook of Population Research for their comments on the final manuscript. This study was supported by funding from the European Research Council under the European Union's Horizon 2020 research and innovation programme, Institutional Family Demography (IFAMID) grant agreement no. 694145.

\section{References}

Aassve, A., F. C. Billari and L. Pessin 2016. Trust and fertility dynamics. Social Forces 95(2): 663-692. https://doi.org/10.1093/sf/sow080

Ainslie, G. 1975. Specious reward: A behavioral theory of impulsiveness and impulse control. Psychological Bulletin 82(4): 463-496. https://doi.org/10.1037/h0076860

Ajzen, I. 1991. The theory of planned behavior. Organizational Behavior and Human Decision Processes 50(2): 179-211. https://doi.org/10.1016/0749-5978(91)90020-T

Ajzen, I. 2011. The theory of planned behaviour: Reactions and reflections. Psychology and Health 26(9): 1113-1127. https://doi.org/10.1080/08870446.2011.613995

Ajzen, I. and J. Klobas 2013. Fertility intentions: An approach based on the theory of planned behavior. Demographic Research 29: 203-232. https://doi.org/10.4054/DemRes.2013. 29.8

Archer, M. S. 2007. Making our way through the world: Human reflexivity and social mobility. Cambridge University Press.

Bail, C. A., T. W. Brown and A. Wimmer 2019. Prestige, proximity, and prejudice: How google search terms diffuse across the world. American Journal of Sociology 124(5): 1496-1548. https://doi.org/10.1086/702007

Balbo, N., F. C. Billari and M. Mills 2013. Fertility in advanced societies: A review of research. European Journal of Population/Revue européenne de Démographie 29: 1-38. https://doi.org/10.1007/s10680-012-9277-y

Banerjee, A. and S. Mullainathan 2010. The shape of temptation: Implications for the economic lives of the poor. NBER Working Paper w15973, National Bureau of Economic Research. https://doi.org/10.3386/w15973

Barlow, P., A. Reeves, M. McKee, G. Galea and D. Stuckler 2016. Unhealthy diets, obesity and time discounting: a systematic literature review and network analysis. Obesity reviews 17(9): 810-819. https://doi.org/10.1111/obr.12431 
Barro, R. J. 1999. Ramsey meets Laibson in the neoclassical growth model. The Quarterly Journal of Economics 114(4): 1125-1152. https://doi.org/10.1162/003355399556232

Becker, G. S. 1960. An economic analysis of fertility. In Demographic and economic change in developed countries, 209-240. Columbia University Press.

Becker, G. S. and H. G. Lewis 1973. On the interaction between the quantity and quality of children. Journal of Political Economy 81(2, Part 2): S279-S288. https://doi.org/10.1086/ 260166

Becker, G. S. and R. J. Barro 1986. Altruism and the economic theory of fertility. Population and Development Review 12: 69-76.

Billari, F. C. 2015. Integrating macro-and micro-level approaches in the explanation of population change. Population Studies 69(sup1): S11-S20. https://doi.org/10.1080/ 00324728.2015.1009712

Billari, F. C., T. Frejka, J. Hobcraft, M. Macura and D. J. van de Kaa 2004. Discussion of paper 'Explanations of the fertility crisis in modern societies: A search for commonalities', Population Studies 57(3): 241-263, by John Caldwell and Thomas Schindlmayr. Population Studies 58(1): 77-92. https://doi.org/10.1080/0032472032000183762

Billari, F. C., D. Philipov and M. R. Testa 2009. Attitudes, norms and perceived behavioural control: Explaining fertility intentions in Bulgaria. European Journal of Population/Revue européenne de Démographie 25(4): 439. https://doi.org/10.1007/s10680-009-9187-9

Billari, F. C., O. Giuntella and L. Stella 2019. Does broadband Internet affect fertility? Population Studies 73(3): 297-316. https://doi.org/10.1080/00324728.2019.1584327

Bongaarts, J. 1990. The measurement of wanted fertility. Population and Development Review, 487-506.

Bongaarts, J. and S. C. Watkins 1996. Social interactions and contemporary fertility transitions. Population and Development Review 22: 639-682.

Bourgeois-Pichat, J. 1989. La dynamique des populations. Paris: Institut national d'études démographiques.

Caldwell, J. C. 1976. Toward a restatement of demographic transition theory. Population and Development Review 321-366.

Caldwell, J. C. 2004. Demographic theory: A long view. Population and Development Review 30(2): 297-316. https://doi.org/10.1111/j.1728-4457.2004.014_1.x

Caldwell, J. C. and T. Schindlmayr 2003. Explanations of the fertility crisis in modern societies: A search for commonalities. Population Studies 57(3): 241-263. https://doi.org/ $10.1080 / 0032472032000137790$

Caldwell, J. C. and T. Schindlmayr 2004. Reply to the discussion of our paper 'Explanations of the fertility crisis in modern societies: A search for commonalities'. Population Studies 58(1): 93-94. https://doi.org/10.1080/0032472032000183771

Carr-Saunders, A. M. 1922. The population problem: A study in human evolution. Oxford: Clarendon Press.

Carrière-Swallow, Y. and F. Labbé 2013. Nowcasting with Google Trends in an emerging market. Journal of Forecasting 32(4): 289-298. https://doi.org/10.1002/for.1252

Coale, A. J. 1973. The demographic transition reconsidered. In International Population Conference, Liège, 1973, Vol. 1, 53-72. Liège: International Union for the Scientific Study of Population. 
Diamond, P. and B. Kőszegi 2003. Quasi-hyperbolic discounting and retirement. Journal of Public Economics 87(9-10): 1839-1872. https://doi.org/10.1016/S0047-2727(02)00041-5

Esping-Andersen, G. and F. C. Billari 2015. Re-theorizing family demographics. Population and Development Review 41(1): 1-31. https://doi.org/10.1111/j.1728-4457.2015.00024.x

Falk, A., A. Becker, T. J. Dohmen, D. Huffman and U. Sunde 2016. The preference survey module: A validated instrument for measuring risk, time, and social preferences. IZA Discussion Paper No. 9674, Bonn: Institute for the Study of Labor.

Falk, A., A. Becker, T. Dohmen, B. Enke, D. Huffman and U. Sunde 2018. Global evidence on economic preferences. The Quarterly Journal of Economics 133(4): 1645-1692. https: //doi.org/10.1093/qje/qjy013

Fatehkia, M., R. Kashyap and I. Weber 2018. Using Facebook ad data to track the global digital gender gap. World Development 107: 189-209. https://doi.org/10.1016/j.worlddev. 2018.03.007

Fehr, E. 2002. Behavioural science: The economics of impatience. Nature 415(6869): 269-272. https://doi.org/10.1038/415269a

Galor, O. and Ö. Özak 2016. The agricultural origins of time preference. American Economic Review 106(10): 3064-3103. https://doi.org/10.1257/aer.20150020

Garcia, D., Y. M. Kassa, A. Cuevas, M. Cebrian, E. Moro, I. Rahwan and R. Cuevas 2018. Analyzing gender inequality through large-scale Facebook advertising data. Proceedings of the National Academy of Sciences 115(27): 6958-6963. https://doi.org/10.1073/pnas. 1717781115

Gecas, V. 1994. In search of the real self: Problems of authenticity in modern times. In Self, collective behavior, and society: Essays honoring the contributions of Ralph H. Turner, eds G. M. Platt and C. Gordon, 139-54. Emerald Publishing Limited.

Goldstein, J., W. Lutz and M. R. Testa 2003. The emergence of sub-replacement family size ideals in Europe. Population Research and Policy Review 22(5-6): 479-496. https://doi.org/10.1023/B:POPU.0000020962.80895.4a

Goldthorpe, J. H. 2016. Sociology as a population science. Cambridge University Press. https://doi.org/10.1017/CBO9781316412565

Gruber, J. and B. Kőszegi 2002. A theory of government regulation of addictive bads: optimal tax levels and tax incidence for cigarette excise taxation. NBER Working Paper No. w8777, National Bureau of Economic Research. https://doi.org/10.3386/w8777

Hagewen, K. J. and S. P. Morgan 2005. Intended and ideal family size in the United States, 1970-2002. Population and Development Review 31(3): 507-527. https://doi.org/10.1111/ j.1728-4457.2005.00081.x

Hariri, A. R., S. M. Brown, D. E. Williamson, J. D. Flory, H. de Wit and S. B. Manuck 2006. Preference for immediate over delayed rewards is associated with magnitude of ventral striatal activity. Journal of Neuroscience 26(51): 13213-13217. https://doi.org/10.1523/ JNEUROSCI.3446-06.2006

Harris, C. and D. Laibson 2001. Dynamic choices of hyperbolic consumers. Econometrica 69(4): 935-957. https://doi.org/10.1111/1468-0262.00225

Haushofer, J. and E. Fehr 2014. On the psychology of poverty. Science 344(6186): 862-867. https://doi.org/10.1126/science.1232491 
Hofstede, G. 1991. Cultures and organizations: Software of the mind. New York: McGrawHill.

Hofstede, G., G. J. Hofstede and M. Minkov 2010. Cultures and organizations: Software of the mind. Revised 3rd edition. New York: McGraw-Hill.

Kirk, D. 1996. Demographic transition theory. Population Studies 50(3): 361-387. https://doi.org/10.1080/0032472031000149536

Kosse, F. and F. Pfeiffer 2013. Quasi-hyperbolic time preferences and their intergenerational transmission. Applied Economics Letters 20(10): 983-986. https://doi.org/10.1080/ 13504851.2013.767974

Laibson, D. 1997. Golden eggs and hyperbolic discounting. The Quarterly Journal of Economics 112(2): 443-478. https://doi.org/10.1162/003355397555253

Lanjouw, P. and M. Ravallion 1995. Poverty and household size. The Economic Journal 105(433): 1415-1434. https://doi.org/10.2307/2235108

Liefbroer, A. C. 2009. Changes in family size intentions across young adulthood: A lifecourse perspective. European Journal of Population/Revue européenne de Démographie 25(4): 363-386. https://doi.org/10.1007/s10680-008-9173-7

Loewenstein, G. and R. H. Thaler 1989. Anomalies: Intertemporal choice. Journal of Economic Perspectives 3(4): 181-193. https://doi.org/10.1257/jep.3.4.181

Luci-Greulich, A. and O. Thévenon 2014. Does economic advancement 'cause' a re-increase in fertility? An empirical analysis for OECD countries (1960-2007). European Journal of Population 30(2): 187-221. https://doi.org/10.1007/s10680-013-9309-2

Lutz, W., V. Skirbekk and M. R. Testa 2006. The low-fertility trap hypothesis: Forces that may lead to further postponement and fewer births in Europe. Vienna Yearbook of Population Research 4: 167-192. https://doi.org/10.1553/populationyearbook2006s 167

McAdams, D. P. 2001. The psychology of life stories. Review of General Psychology 5(2): 100-122. https://doi.org/10.1037\%2F1089-2680.5.2.100

McDonald, P. 1996. Demographic life transitions: An alternative theoretical paradigm. Health Transition Review, Supplement 6: 385-392.

McDonald, P. 2001. Theory pertaining to low fertility. ANU Research Publications. https: //openresearch-repository.anu.edu.au/handle/1885/41443

McEachan, R. R. C., M. Conner, N. Taylor and R. J. Lawton 2011. Prospective prediction of health-related behaviors with the theory of planned behavior: A meta-analysis. Health Psychology Review 5: 97-144. https://doi.org/10.1080/17437199.2010.521684

Mencarini, L., D. Vignoli and A. Gottard 2015. Fertility intentions and outcomes: Implementing the theory of planned behavior with graphical models. Advances in Life Course Research 23: 14-28. https://doi.org/10.1016/j.alcr.2014.12.004

Mills, M., K. Begall, L. Mencarini and M. L. Tanturri 2008. Gender equity and fertility intentions in Italy and the Netherlands. Demographic Research 18: 1-26. https://doi.org/ 10.4054/DemRes.2008.18.1

Morgan, S. P. 2001. Should fertility intentions inform fertility forecasts. Proceedings of US Census Bureau Conference: The Direction of Fertility in the United States. Washington, DC: US Census Bureau.

Myrskylä, M., H. P. Kohler and F. C. Billari 2009. Advances in development reverse fertility declines. Nature 460(7256): 741-743. https://doi.org/10.1038/nature08230 
Notestein, F. W. 1945. Population: The long view. In Food for the World, eds T. Schultz, 36-58. Chicago: Chicago University Press.

Philipov, D. 2011. Theories on fertility intentions: A demographer's perspective. Vienna Yearbook of Population Research 9: 37-45. https://doi.org/10.1553/ populationyearbook2011s37

Philipov, D., Z. Spéder and F. C. Billari 2006. Soon, later, or ever? The impact of anomie and social capital on fertility intentions in Bulgaria (2002) and Hungary (2001). Population Studies 60(3): 289-308. https://doi.org/10.1080/00324720600896080

Preis, T., H. S. Moat, H. E. Stanley and S. R. Bishop 2012. Quantifying the advantage of looking forward. Scientific Reports 2: 350. https://doi.org/10.1038/srep00350

Ragnedda, M. and G. W. Muschert, eds 2013. The digital divide: The Internet and social inequality in international perspective. Routledge.

Régnier-Loilier, A., D. Vignoli and C. Dutreuilh 2011. Fertility intentions and obstacles to their realization in France and Italy. Population 66(2): 361-389.

Robson, A. J. and B. Szentes 2014. A biological theory of social discounting. American Economic Review 104(11): 3481-97. https://doi.org/10.1257/aer.104.11.3481

Salanié, F. and N. Treich 2006. Over-savings and hyperbolic discounting. European Economic Review 50(6): 1557-1570. https://doi.org/10.1016/j.euroecorev.2005.05.003

Schoen, R., N. M. Astone, Y. J. Kim, C. A. Nathanson and J. M. Fields 1999. Do fertility intentions affect fertility behavior? Journal of Marriage and Family 61(3): 790-799. https://psycnet.apa.org/doi/10.2307/353578

Simon, J. L. 1974. The effects of income on fertility. Carolina Population Center, Monograph No. 19, University of North Carolina at Chapel Hill.

Sobotka, T. 2009. Sub-replacement fertility intentions in Austria. European Journal of Population / Revue européenne de Démographie 25: 387. https://doi.org/10.1007/s10680009-9183-0

Strotz, R. H. 1955. Myopia and inconsistency in dynamic utility maximization. The Review of Economic Studies 23(3): 165-180. https://doi.org/10.2307/2295722

Thaler, R. H. 1981. Some empirical evidence on dynamic inconsistency. Economics Letters 8(3): 201-207. https://doi.org/10.1016/0165-1765(81)90067-7

Thaler, R. H. 2018. From cashews to nudges: The evolution of behavioral economics. American Economic Review 108(6): 1265-1287. https://doi.org/10.1257/aer.108.6.1265

Van de Walle, E. 1992. Fertility transition, conscious choice, and numeracy. Demography 29(4): 487-502. https://doi.org/10.2307/2061848

Westoff, C. F., E. G. Mishler and E. L. Kelly 1957. Preferences in size of family and eventual fertility twenty years after. American Journal of Sociology 62(5): 491-497. https://doi.org/10.1086/222079

Wigniolle, B. 2013. Fertility in the absence of self-control. Mathematical Social Sciences 66(1): 71-86. https://doi.org/10.1016/j.mathsocsci.2013.02.001

World Bank. 2018. The human capital project. Washington, DC: World Bank.

Wrede, M. 2011. Hyperbolic discounting and fertility. Journal of Population Economics 24(3): 1053-1070. https://doi.org/10.1007/s00148-009-0283-2

Zagheni, E. and I. Weber 2012. You are where you e-mail: Using e-mail data to estimate international migration rates. In WebSci'12: Proceedings of the 4th annual ACM Web 
Science Conference, 348-351. Association for Computing Machinery. https://doi.org/10. $1145 / 2380718.2380764$

Zagheni, E. and I. Weber 2015. Demographic research with non-representative internet data. International Journal of Manpower 36(1): 13-25. https://doi.org/10.1108/IJM-122014-0261

Open Access This article is published under the terms of the Creative Commons Attribution 4.0 International License (https://creativecommons.org/licenses/by/4.0/) that allows the sharing, use and adaptation in any medium, provided that the user gives appropriate credit, provides a link to the license, and indicates if changes were made. 
